\title{
Template-Free Hydrothermal Synthesis of $\beta$-FeOOH Nanorods and Their Catalytic Activity in the Degradation of Methyl Orange by a Photo-Fenton-Like Process
}

\author{
Zhihui Xu ${ }^{1}$, Jianru Liang ${ }^{2}$, Lixiang Zhou ${ }^{2 *}$ \\ ${ }^{1}$ Department of Chemistry, College of Science, Nanjing Agricultural University, Nanjing, China \\ ${ }^{2}$ Department of Environmental Engineering, College of Resources and Environmental Sciences, Nanjing Agricultural University, \\ Nanjing, China \\ Email: ${ }^{*} 1 x z h o u @$ njau.edu.cn
}

Received June 14, 2013; revised July 21, 2013; accepted September 15, 2013

Copyright (C) 2013 Zhihui Xu et al. This is an open access article distributed under the Creative Commons Attribution License, which permits unrestricted use, distribution, and reproduction in any medium, provided the original work is properly cited.

\begin{abstract}
The rod-shaped form of crystalline $\beta$ - $\mathrm{FeOOH}$ (akaganeite) was prepared by the template-free hydrothermal method with urea as the homogeneous precipitant. X-ray diffraction, field-emission scanning electron microscope and Fourier transform infrared spectrum were used to characterize the resulting products. The degradation of methyl orange (MO) was studied using the prepared nanostructure materials in a photo-Fenton-like process. MO degradation was effectively achieved by hydroxyl radicals that were generated in the heterogeneous catalysis process. Specific surface area of the prepared $\beta$ - $\mathrm{FeOOH}$ was an important factor affecting the efficiency of MO degradation, which depended on the synthesis conditions such as the reaction temperature, the initial concentration of urea and $\mathrm{FeCl}_{3} \cdot 6 \mathrm{H}_{2} \mathrm{O}$ as well as the $\mathrm{n}(\mathrm{urea}) / \mathrm{n}\left(\mathrm{Fe}^{3+}\right)$ ratio. The photodegradation efficiencies slightly decreased with the increase of initial $\mathrm{pH}$ in the range of 4.5 - 9.5, which indicated the prepared $\beta$-FeOOH catalyst can well overcome the drawback of a narrow $\mathrm{pH}$ range of homogeneous Fenton reaction. $\beta$-FeOOH catalysts loading and $\mathrm{H}_{2} \mathrm{O}_{2}$ concentration also play important effect on the degradation efficiency of MO. The prepared $\beta$-FeOOH showed good ability of reuse for multiple trials.
\end{abstract}

Keywords: $\beta$-FeOOH; Heterogeneous; Photocatalysis; Fenton Reaction; Template-Free Hydrothermal Synthesis

\section{Introduction}

Azo dyes are widely used in industries such as textiles, foodstuffs and leather and about $15 \%$ of them end up in wastewaters [1]. Release of these colored wastewaters poses a serious threat to the environment. Decolorization treatment of azo dye effluents has therefore attracted a great deal of attention. Due to the aromatic character of most dye molecules and the stability of modern dyes, traditional physical and/or chemical methods for removal of these dyes are not efficient enough [2,3].

During the last two decades, photo-Fenton reactions have been the subject of numerous investigations as a kind of advanced oxidation processes (AOPs) [4-7]. The reaction process involves in situ generation of highly reactive hydroxyl radicals $(\cdot \mathrm{OH})$, which can oxidize almost all the organic substrates owing to their high oxidation potential $\left(E^{0}=+2.80 \mathrm{~V}\right)$. The main disadvantage of homogeneous Fenton process is the fact that the homo-

\footnotetext{
"Corresponding author.
}

geneous Fenton process is most efficient only in the narrow $\mathrm{pH}$ range of $2.5-3$. Below this $\mathrm{pH}$, the hydroxyl radicals are scavenged by protons and the concentration of $\mathrm{Fe}(\mathrm{III})(\mathrm{OH})^{2+}$, representing the photo-active species. The hydroxyl radicals decline above this PH. The generation of undesirable iron-containing sludges, which creates disposal and other environmental problems [8,9], is another drawback of homogeneous Fenton process. To solve all these drawbacks, modified heterogeneous Fenton-based processes are of particular interests. In the heterogeneous catalysis processes, the Fe(III) species are immobilized within the structure of solid catalyst. Therefore, iron hydroxide precipitation is prevented and the catalyst enables operation at a wide range of $\mathrm{pH}$ with approximate efficiency as that in acidic solutions.

Akaganeite $(\beta$ - $\mathrm{FeOOH})$ has a tetragonal structure consisting of double chains of edge-shared octahedral that share corners with adjacent chains to form channels running parallel to the $c$-axis [10]. A certain number of extraframwork anions such as halide ions are necessary in 
the structure to balance the extra protonation of oxdide in the iron octahedral since akaganeite is synthesized in acidic solution. This tunnel structure makes $\beta$-FeOOH an especially interesting material as a promising photo-Fenton catalyst in the heterogeneous system $[11,12]$.

In the present study, we presented a simple and environmentally friendly hydrothermal synthesis route to prepare uniform rod-shaped $\beta$-FeOOH nanostructures without adding any additives, and explore the catalytic activity of the prepared samples for the degradation of methyl orange (MO) in the presence of $\mathrm{H}_{2} \mathrm{O}_{2}$ under UV irradiation. MO was chosen as the target pollutant in this paper because it is stable under ultraviolet (UV) light irradiation and a typical azo dye is widely used in the textile industry.

\section{Materials and Methods}

\subsection{Preparation of Photocatalyst $\beta$-FeOOH}

All chemicals used in this work were of analytical grade, purchased from Shanghai Chemical Reagent Co., Ltd. (China), and used without any further purification.

$\beta$-FeOOH nanostructure was typically synthesized as follows: $0.04 \mathrm{~mol}(10.8116 \mathrm{~g}) \mathrm{FeCl}_{3} \cdot 6 \mathrm{H}_{2} \mathrm{O}$ and $0.04 \mathrm{~mol}$ $(2.4000 \mathrm{~g})$ urea were dissolved in $40.00 \mathrm{ml}$ deionized water under permanent magnetic stirring for 30 minutes. Without adjusting the $\mathrm{pH}$ value, the mixed solution was transferred into a teflon-lined stainless steel autoclave. The sealed autoclave was maintained at $90^{\circ} \mathrm{C}$ for $8 \mathrm{~h}$, and then cooled to room temperature naturally. The resulting product was collected by centrifugation, washed several times with absolute ethanol and deionized water, and finally dried at $60^{\circ} \mathrm{C}$ for $24 \mathrm{~h}$.

\subsection{Photodegradation Procedures}

The photodegradation of MO was carried out in a XPA-7 photochemical reactor (Xujiang electromechanical plant, Nanjing, China). The temperature of reaction solutions was kept at $25 \pm 2^{\circ} \mathrm{C}$ by cooling water circulation. A 500 W medium $\mathrm{Hg}$ lamp was used as an irradiation source. The initial $\mathrm{pH}$ values of reaction solutions were adjusted to 4.5 with dilute sulfuric acid solution and sodium hydroxide solution. The initial concentration of $\mathrm{MO}$ and $\mathrm{H}_{2} \mathrm{O}_{2}$ were $80 \mathrm{mg} \cdot \mathrm{L}^{-1}$ and $500 \mathrm{mg} \cdot \mathrm{L}^{-1}$, respectively, with a catalyst loading of $200 \mathrm{mg} \cdot \mathrm{L}^{-1}$. At given irradiation time intervals, a small quantity of solution was taken and centrifuged to separate the catalyst particles from the solution. The concentration of MO was determined by using a UV-vis spectrophotometer (Beijing Ruili Corp., UV-9100) at $464 \mathrm{~nm}$. The degradation efficiency was calculated with the following formula:

$$
\eta_{D}=\left(C_{0}-C_{t}\right) / C_{0} \times 100 \%
$$

where $\eta_{D}$ is the degradation efficiency of $\mathrm{MO}, C_{0}$ and $C_{t}$ are the concentration of MO solution at initial time and after irradiated at $t$ time, respectively.

\subsection{Catalyst Characterization}

The powder X-ray diffraction (XRD) patterns were recorded at a scanning rate of $4^{\circ} \mathrm{min}^{-1}$ in the $2 \theta$ range of $10-80^{\circ}$ using a Bruker D8 Advance instrument with $\mathrm{Cu}$ - K $\alpha$ radiation $(\lambda=1.5406 \AA)$ at room temperature. The morphologies and nanostructures of synthesized products were further observed using a Hitachi S-4800 fieldemission scanning electron microscope (FE-SEM) at the acceleration voltage $10 \mathrm{kV}$. Fourier transform infrared spectrum (FTIR) measurements were performed on a Bruker Vector 22 FT-IR spectrophotometer, with scanning from 4000 to $400 \mathrm{~cm}^{-1}$ using $\mathrm{KBr}$ pellets. The specific surface area of the prepared catalysts was determined by the $\mathrm{N}_{2}$ adsorption isotherms obtained at $-196^{\circ} \mathrm{C}$ using a surface area analyzer JW-04 (Beijing Jingweibo Science and Technology Co., Ltd.). Each sample was degassed under vacuum for $2 \mathrm{~h}$ at $105^{\circ} \mathrm{C}$ prior to the analysis.

\section{Results and Discussion}

\subsection{Characterization of Synthesized Catalysts}

Generally, the FeOOH catalysts were prepared by slowly dropping dilute alkali into $\mathrm{Fe}^{3+}$ solution under vigorous stirring [10,12-14], which could not be easy to control purity and morphology of the end product. Here, urea was used as precipitant for $\mathrm{Fe}^{3+}$ ions. Urea was hydrolyzed and $\mathrm{OH}^{-}$ions were released homogeneously into the reaction solution. The formation process of $\beta-\mathrm{FeOOH}$ can be described as follows [15]:

$$
\begin{gathered}
\mathrm{CO}\left(\mathrm{NH}_{2}\right)_{2}+\mathrm{H}_{2} \mathrm{O} \rightarrow 2 \mathrm{NH}_{3}+\mathrm{CO}_{2} \\
\mathrm{NH}_{3}+\mathrm{H}_{2} \mathrm{O} \rightarrow \mathrm{NH}_{4}^{+}+\mathrm{OH}^{-} \\
\mathrm{Fe}^{3+}+3 \mathrm{OH}^{-} \rightarrow \mathrm{Fe}(\mathrm{OH})_{3} \\
\mathrm{Fe}(\mathrm{OH})_{3} \rightarrow \beta-\mathrm{FeOOH}+\mathrm{H}_{2} \mathrm{O}
\end{gathered}
$$

The mineral phase and its purity of the as-synthesized products were identified by XRD. Figure 1 presents the XRD patterns of the as-prepared products with different reaction temperature. All the diffraction peaks can be well indexed to pure tetragonal $\beta$-FeOOH phase structure (JCPDS card no. 34 - 1266) with cell constants $a=$ $10.535 \AA$ and $c=3.03 \AA$ (calculated by MDI JADE software). No other characteristic peaks were detected for impurities such as $\alpha-\mathrm{FeOOH}, \gamma-\mathrm{FeOOH}$, and $\alpha-\mathrm{Fe}_{2} \mathrm{O}_{3}$. All the strong and sharp diffraction peaks indicated the good crystallization of the as-synthesized samples.

Figure 2 shows the FE-SEM images of $\beta$-FeOOH obtained at different reaction temperature. All samples ex- 


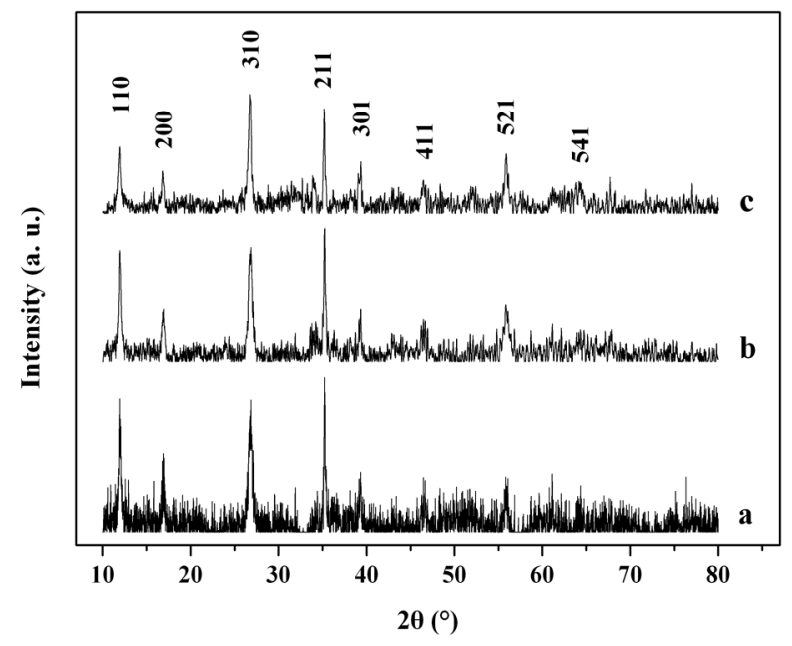

Figure 1. XRD patterns of the samples obtained at different reaction temperature: a $70^{\circ} \mathrm{C}, \mathrm{b} 90^{\circ} \mathrm{C}, \mathrm{c} 110^{\circ} \mathrm{C}$.

hibit rod-like shape. The sample, synthesized at $70^{\circ} \mathrm{C}$, presented average diameter of about $70 \mathrm{~nm}$ and length of about $400 \mathrm{~nm}$ (Figure 2(a)). Both the average length and the diameter of the as-obtained nanorods increased with the increase of reaction temperature. When the sample was synthesized at $90^{\circ} \mathrm{C}$, nanorods with average diameter of about $83 \mathrm{~nm}$ and length of about $880 \mathrm{~nm}$ were formed as shown in Figure 2(b). Furthermore, it is found in Figure 2(c) that the FE-SEM image of the sample prepared at $110^{\circ} \mathrm{C}$ was with average diameter of about 120 $\mathrm{nm}$ and length of about $2.3 \mu \mathrm{m}$. However, as shown in Figure 2, the distributions of the particle sizes of $110^{\circ} \mathrm{C}$ synthesized samples are not as homogeneous as those synthesized at $90^{\circ} \mathrm{C}$ and $70^{\circ} \mathrm{C}$.

\subsection{Photodegradation of $\mathrm{MO}$ by $\beta-\mathrm{FeOOH} / \mathrm{H}_{2} \mathrm{O}_{2}$ with or without UV Irradiation}

The degradation efficiency of MO with irradiation time under different conditions is illustrated in Figure 3. Negligible degradation of $\mathrm{MO}$ was observed over 60 minutes of irradiation in the absence of $\beta$-FeOOH and $\mathrm{H}_{2} \mathrm{O}_{2}$ (Figure 3(a)), which showed the stability of MO molecular only under UV light irradiation. After adding $\beta$-FeOOH to $\mathrm{MO}$ solution, the MO reduction of about $37 \%$ occurred under UV irradiation for 60 minutes (Figure 3(b)), which might be attributed to the adsorption of $\mathrm{MO}$ by the catalyst. However, in the $\beta$-FeOOH$/ \mathrm{H}_{2} \mathrm{O}_{2}$ suspension without UV irradiation, the degradation efficiency of MO was increased to about $90 \%$ after 60 minutes (Figure 3(c)). Furthermore, MO was degraded almost completely in the presence of $\beta$-FeOOH and $\mathrm{H}_{2} \mathrm{O}_{2}$ under UV light irradiation (Figure 3(d)). Obviously, UV radiation can accelerate the heterogeneous Fenton reaction owing to the enhancement of $\bullet \mathrm{OH}$ production with comparison to that in the dark. In the light of above results, it is presumed that both $\beta$-FeOOH and $\mathrm{H}_{2} \mathrm{O}_{2}$ are

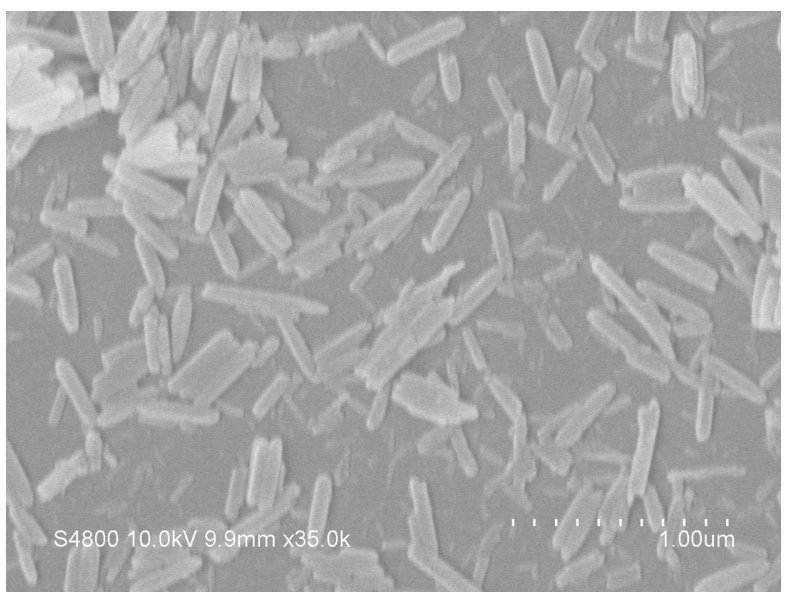

(a)

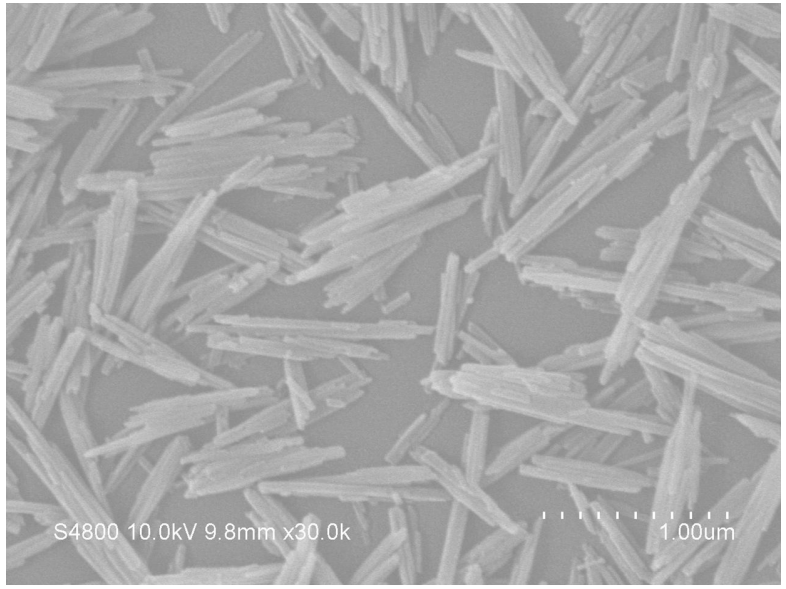

(b)

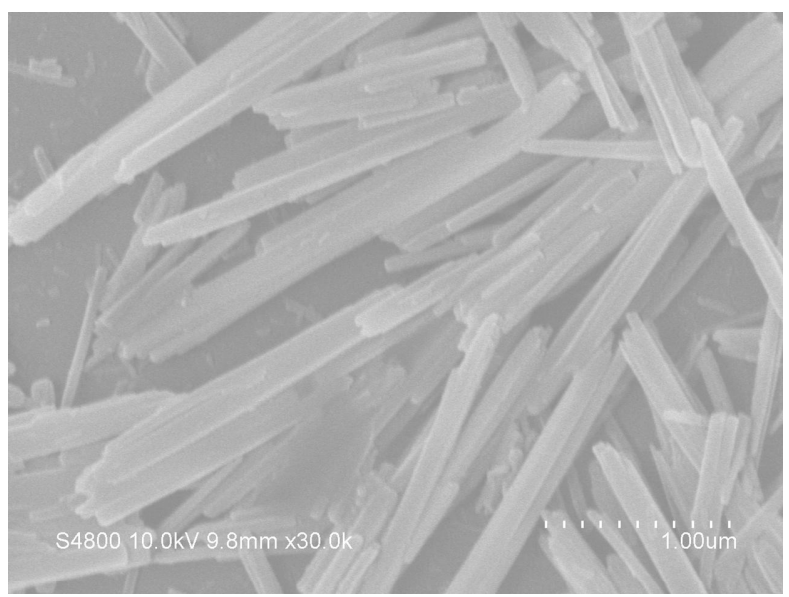

(c)

Figure 2. FE-SEM images of the $\beta$-FeOOH obtained at different reaction temperature: $7^{\circ} \mathrm{C}, \mathrm{b} 90^{\circ} \mathrm{C}, \mathrm{c} 110^{\circ} \mathrm{C}$.

prerequisite for the heterogeneous Fenton reaction. The $\beta$-FeOOH catalyst experiences an iron cycling occurred mostly on the catalyst surface, where the hydroxyl radicals are generated, without significant iron diffusion into the solution phase. The MO adsorbed on the surface of 


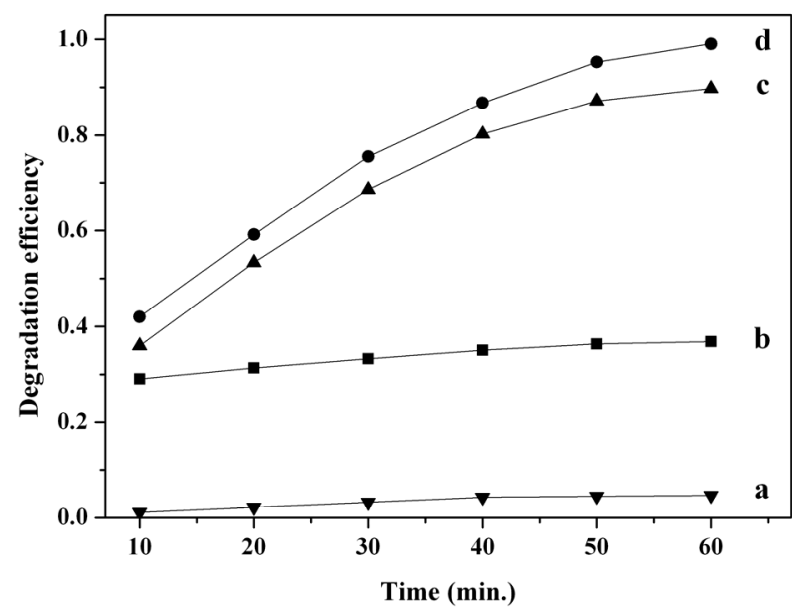

Figure 3. The degradation efficiency of MO under different conditions: a only MO solution under UV irradiation, b in the presence of $\beta$-FeOOH under UV irradiation, $c$ in the presence of $\beta$-FeOOH and $\mathrm{H}_{2} \mathrm{O}_{2}$ in the dark, $d$ in the presence of $\beta$-FeOOH and $\mathrm{H}_{2} \mathrm{O}_{2}$ under $\mathrm{UV}$ irradiation.

catalyst can be attacked by hydroxyl radicals and degraded into intermediate compounds and eventually mineralized into $\mathrm{CO}_{2}$ and $\mathrm{H}_{2} \mathrm{O}$. Therefore, the homogeneous photo-Fenton reaction in the bulk solution contributed little to the degradation of MO $[5,16]$.

To verify the adsorption of $\mathrm{MO}, \beta-\mathrm{FeOOH}$ was dipped into methyl orange solution for $0.5 \mathrm{~h}$, then separated, rinsed with water and dried at $60^{\circ} \mathrm{C}$ for $24 \mathrm{~h}$. FTIR technique was applied to examine $\mathrm{MO}$ before and after the adsorption by $\beta-\mathrm{FeOOH}$. Infrared analysis of $\beta$ - $\mathrm{FeOOH}$ samples in the dark-Fenton process and in the photoFenton process were also conducted and shown in Figure 4. In the infrared spectrum of $\beta$-FeOOH adsorbed with methyl orange (Figure 4(b)), relative strength of the absorption peaks changed greatly compared with that of pure MO (Figure 4(a)). The absorption peaks below $1604 \mathrm{~cm}^{-1}$ become much weaker in Figure 4(b), which indicates that $\beta$-FeOOH has strong adsorption effect with $\mathrm{MO}$ and results in the change of electric cloud distribution within the MO molecules. In the infrared spectrum of $\beta$-FeOOH samples after the dark-Fenton process and the photo-Fenton process, the absorption peaks at wavelength $1628,1392,1132$ and $1060 \mathrm{~cm}^{-1}$ were attributed to the O-H vibrations of absorbed $\mathrm{H}_{2} \mathrm{O}$ molecules or structural $\mathrm{OH}$ groups $[15,17]$. The other absorption peaks at wavelength 844,696 and $634 \mathrm{~cm}^{-1}$ were assigned to the $\mathrm{Fe}-\mathrm{O}$ vibration modes in $\beta$ - $\mathrm{FeOOH}[15,18,19]$. No characteristic absorption peaks ascribed to the MO were observed in the both dark-Fenton process and photoFenton process, which implied that the MO degradation rate on the $\beta$-FeOOH surface was quite fast. The pseudofirst order reaction kinetics constants of the MO degradation were calculated to be $0.03224 \mathrm{~min}^{-1}\left(\mathrm{R}^{2} 0.990\right)$ for the dark-Fenton process and $0.04267 \mathrm{~min}^{-1}\left(\mathrm{R}^{2} 0.993\right)$

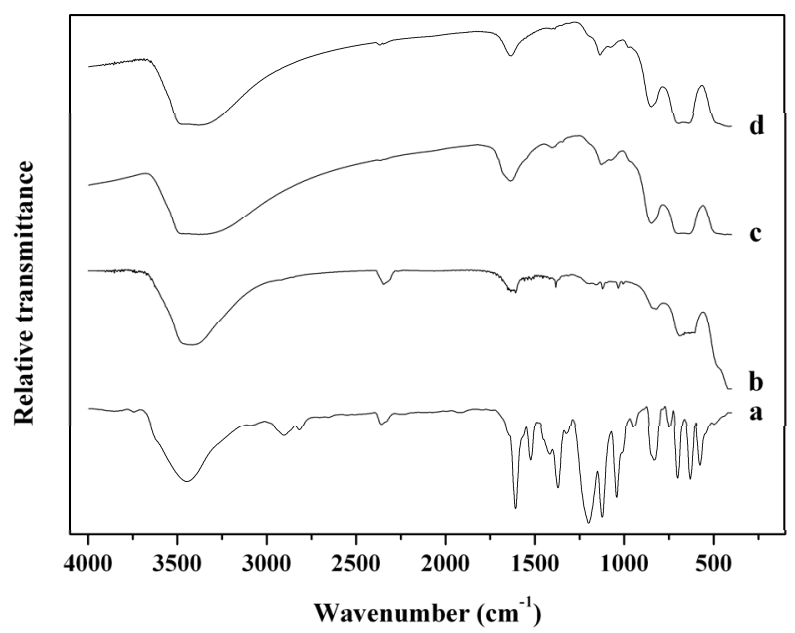

Figure 4. FTIR spectra of pure methyl orange (a), $\beta$ $\mathrm{FeOOH}$ adsorbed with methyl orange (b), $\beta$ - $\mathrm{FeOOH}$ in the dark-Fenton process (c), $\beta$-FeOOH in the photo-Fenton process (d).

for the photo-Fenton process, respectively.

\subsection{Effect of Initial pH on MO Photodegradation}

The effects of initial $\mathrm{pH}$ on the removal of $\mathrm{MO}$ with $\beta$ - $\mathrm{FeOOH} / \mathrm{H}_{2} \mathrm{O}_{2}$ under UV irradiation were determined with a $\mathrm{pH}$ range of $4.5-9.5$. As shown in Figure 5, the MO photo-degradation process remained efficient at $\mathrm{pH}$ as high as $\mathrm{pH} 9.5$ with degradation efficiency of $96.5 \%$ after UV irradiation for 60 minutes. As the initial $\mathrm{pH}$ decreased, the degradation efficiency of MO increased to $98.8 \%$ at $\mathrm{pH} 7.0$ and $99.1 \%$ at $\mathrm{pH}$ 4.5. Many studies had reported that initial solution $\mathrm{pH}$ dramatically influence homogeneous Fenton reaction efficiency $[5,12,16]$. At neutral $\mathrm{pH}$, the homogeneous photo-degradation efficiency can nearly be neglected because of iron precipitation. The results obtained in the present study indicate that the prepared $\beta-\mathrm{FeOOH}$ as heterogeneous catalyst can overcome the drawback of a narrow $\mathrm{pH}$ range of homogeneous Fenton reaction. The reason why the degradation efficiency of MO slightly decreased with the increase of $\mathrm{pH}$ could be explained by the different adsorption of organic compounds on catalyst surface. The adsorption of $\mathrm{MO}$ on $\beta-\mathrm{FeOOH}$ surface is the first and indispensable stage for its further decomposition into $\mathrm{CO}_{2}$ and $\mathrm{H}_{2} \mathrm{O}$. Iron oxides, whether they have a particular crystal structure or not, typically have point of zero charge (PZC) in the $\mathrm{pH}$ range of 7 - 9 [16]. The acid/base property of the $\beta$ - $\mathrm{FeOOH}$ surface hydroxyl groups can be changed with the conversion of $\mathrm{pH}_{\mathrm{PZC}}$ and $\mathrm{pH}$ (as shown in Equations (6) and (7)) [20,21].

$$
\begin{aligned}
& \equiv \mathrm{FeOH}+\mathrm{H}^{+} \leftrightarrow \equiv \mathrm{FeOH}_{2}^{+} \quad\left(\mathrm{pH}<\mathrm{pH}_{\mathrm{PZC}}\right) \quad K_{1}^{\text {int }} \\
& \equiv \mathrm{FeOH} \leftrightarrow \equiv \mathrm{FeO}^{-}+\mathrm{H}^{+} \quad\left(\mathrm{pH}>\mathrm{pH}_{\mathrm{PZC}}\right) \quad K_{2}^{\text {int }}
\end{aligned}
$$




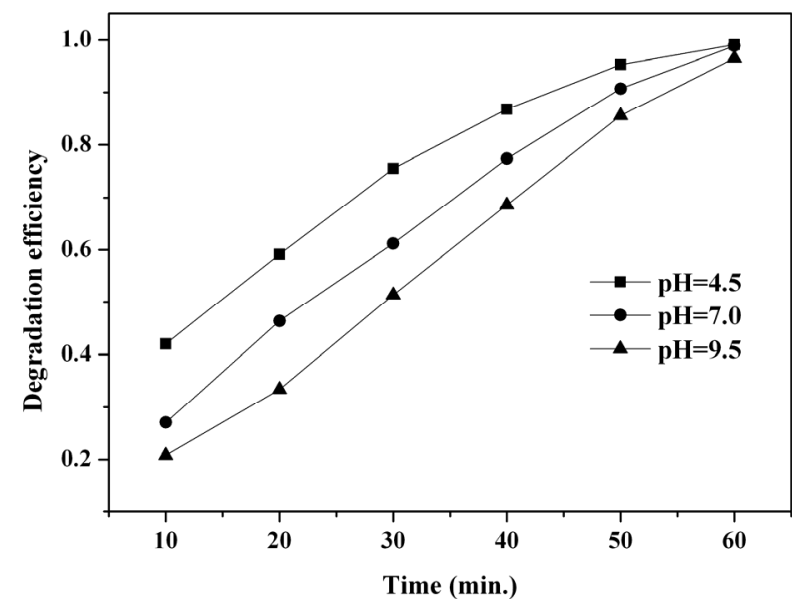

Figure 5. Effect of initial pH on MO degradation efficiency.

where $K_{1}^{\text {int }}$ and $K_{2}^{\text {int }}$ are the intrinsic ionization constants. When the solution $\mathrm{pH}$ is near the $\mathrm{pH}_{\mathrm{PZC}}$, most of surface hydroxyls exist in neutral state. Otherwise, the oxide surface becomes protonated or deprotonated when solution $\mathrm{pH}$ is below or above its $\mathrm{pH}_{\mathrm{PZC}}$. At $\mathrm{pH} 4.5$, the electrostatic attraction between the positively charged $\beta$-FeOOH surface $\left(\mathrm{FeOH}_{2}^{+}\right)$and negatively charged sulfonic group of $\mathrm{MO}$ molecular leads to strong adsorption. The neutral hydroxyl group $(\mathrm{FeOH})$ is the predominant species on $\beta$-FeOOH surface at $\mathrm{pH} 7.0$, which decreases the binding strength of $\beta$-FeOOH with $\mathrm{MO}$ molecular. When $\mathrm{pH} 9.5$, the surface of $\beta$-FeOOH is gradually deprotonated to the negative ions $\left(\mathrm{FeO}^{-}\right.$causing the repulsion with MO molecular.

\subsection{Effect of $\beta$-FeOOH Loading on MO Photodegradation}

$\beta$-FeOOH acted as catalysts in the MO photodegradation reaction. In this case, four concentrations of $\beta-\mathrm{FeOOH}$, such as $50,100,200$ and $400 \mathrm{mg} \cdot \mathrm{L}^{-1}$, were selected to study the catalysts loading on the MO degradation. As shown in Figure 6, when $\beta$-FeOOH loading was increased from $50 \mathrm{mg} \cdot \mathrm{L}^{-1}$ to $200 \mathrm{mg} \cdot \mathrm{L}^{-1}$, the time required to complete degradation of methyl orange declined from 90 minutes to 60 minutes. On increasing $\beta$-FeOOH loading to $400 \mathrm{mg} \cdot \mathrm{L}^{-1}$, MO had totally degraded after 80 minutes. Obviously, the degradation efficiency of MO is directly related to the level of catalysts loading. However, when catalyst loading reaches certain value, the screening effect of UV light by catalyst powders arises, which leads to the decrease of MO degradation efficiency.

\subsection{Effect of $\mathrm{H}_{2} \mathrm{O}_{2}$ Concentration on Photodegradation Efficiency of MO}

Since the concentration of hydrogen peroxide is directly related to the amount of hydroxyl radicals produced in the catalytic reaction, this parameter influences degrada-

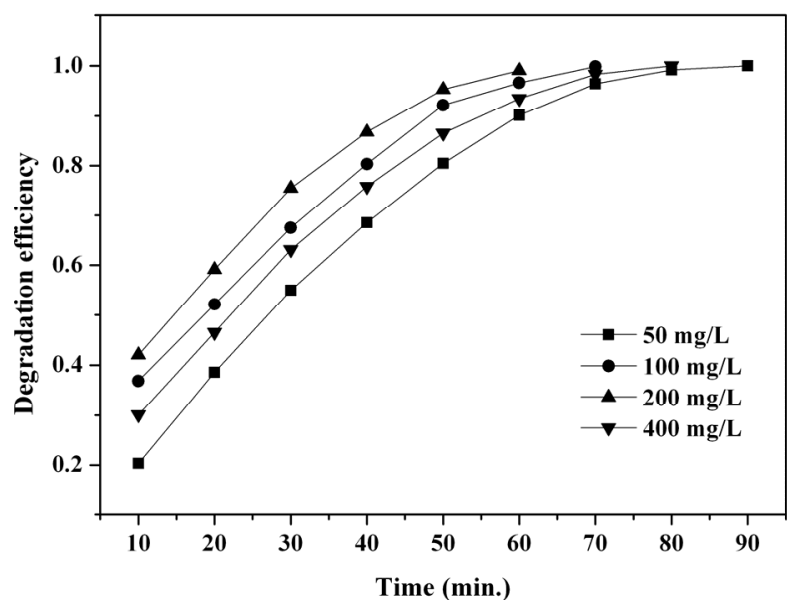

Figure 6. Effect of $\beta$-FeOOH loading on MO photocatalysis degradation efficiency.

tion efficiency. We selected four concentrations of $\mathrm{H}_{2} \mathrm{O}_{2}$, such as $250,500,1000$ and $2000 \mathrm{mg} \cdot \mathrm{L}^{-1}$, to investigate the effect of $\mathrm{H}_{2} \mathrm{O}_{2}$ concentration on photodegradation efficiency of MO. As shown in Figure 7, when the $\mathrm{H}_{2} \mathrm{O}_{2}$ concentration was increased from 250 to $1000 \mathrm{mg} \cdot \mathrm{L}^{-1}$, the photodegradation efficiency of MO increased. However, when the $\mathrm{H}_{2} \mathrm{O}_{2}$ concentration reached $2000 \mathrm{mg} \cdot \mathrm{L}^{-1}$, the degradation rate of MO decreased. This was not consistent with our prediction. We postulate that too much $\mathrm{H}_{2} \mathrm{O}_{2}$ is absorbed on the surface of catalysts, impeding adsorption of MO molecular on such surface, and lowering degradation efficiency. At the same time, excessive $\mathrm{H}_{2} \mathrm{O}_{2}$ serves as a scavenging agent of $\bullet \mathrm{OH}$ with the mechanism shown in follow [22].

$$
\begin{gathered}
\bullet \mathrm{OH}+\mathrm{H}_{2} \mathrm{O}_{2} \rightarrow \mathrm{H}_{2} \mathrm{O}+\mathrm{HO}_{2} \bullet \\
\bullet \mathrm{OH}+\mathrm{HO}_{2} \bullet \mathrm{H}_{2} \mathrm{O}+\mathrm{O}_{2}
\end{gathered}
$$

\subsection{Recycles of $\boldsymbol{\beta}$-FeOOH Catalyst}

A good photocatalyst, in addition to its broad $\mathrm{pH}$ range of application and high photocatalytic activity, should exhibit better capacity for multiple uses. Here, four experiments of the photocatalytic regenerability of $\beta$ $\mathrm{FeOOH}$, synthesized at $90^{\circ} \mathrm{C}$, was conducted by a series of systematic experiments and results were presented in Figure 8 and Table 1. After each photocatalytic cycle, the $\beta$-FeOOH catalyst was directly centrifuged and entered into the next photocatalytic cycle without any other post treatment. As seen, the experiment data were well fitted by the pseudo first-order kinetics with regression coefficients higher than 0.990 . After 4 times photocatalytic cycles, the time required to complete degradation of methyl orange increased from 60 minutes to 80 minutes. The catalytic performance of the $\beta$-FeOOH was basically close to the level of the first trial, which indicates the reuse of the $\beta$-FeOOH is cost-effective because the Fen- 


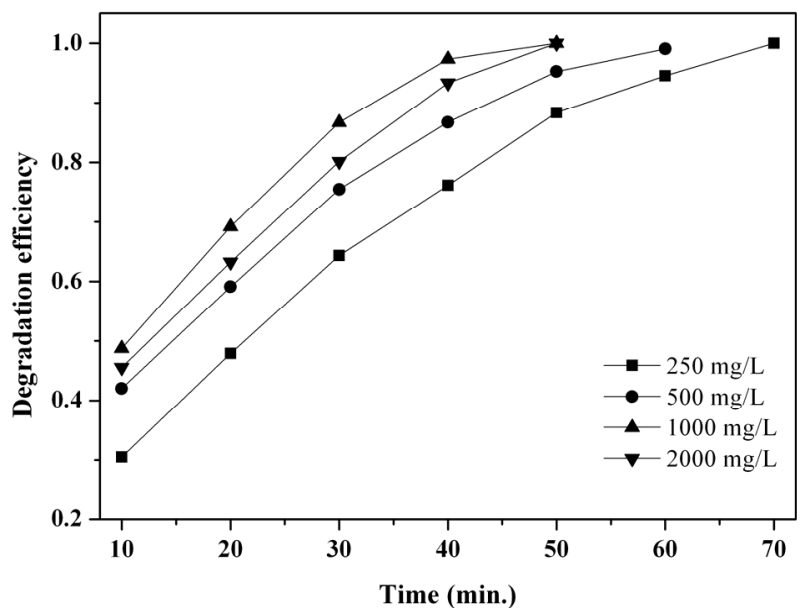

Figure 7. Effect of $\mathrm{H}_{2} \mathrm{O}_{2}$ concentration on photocatalysis efficiency of $\beta$ - $\mathrm{FeOOH}$.

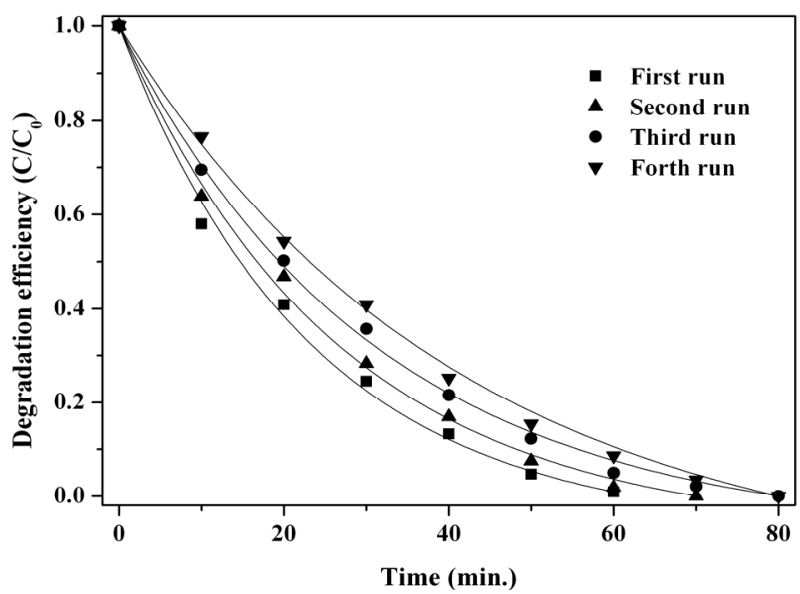

Figure 8. MO removal in multiple uses of $\beta$-FeOOH prepared with the initial urea and $\mathrm{FeCl}_{3} \cdot 6 \mathrm{H}_{2} \mathrm{O}$ concentration of $1.0 \mathrm{~mol} \cdot \mathrm{L}^{-1}$ at $90^{\circ} \mathrm{C}$.

Table 1. Kinetic constants of MO degradation at different runs.

\begin{tabular}{cccc}
\hline Catalyst & Test & $k(\min -1)$ & $\mathrm{R}^{2}$ \\
\hline & $1^{\text {st }}$ run & 0.04267 & 0.993 \\
$\beta$-FeOOH prepared with the initial & $2^{\text {nd }}$ run & 0.03715 & 0.996 \\
$\begin{array}{c}\text { urea and } \mathrm{FeCl}_{3} \cdot 6 \mathrm{H}_{2} \mathrm{O} \text { concentration } \\
\text { of } 1.0 \mathrm{~mol} \cdot \mathrm{L}^{-1} \text { at } 90^{\circ} \mathrm{C}\end{array}$ & $3^{\text {rd }}$ run & 0.03174 & 0.997 \\
& $4^{\text {th }}$ run & 0.02413 & 0.997 \\
\hline
\end{tabular}

ton catalyst does not have to be replaced over a relatively long period.

\subsection{Catalytic Properties of $\beta$-FeOOH Prepared under Different Conditions}

Synthesis conditions, such as the $\mathrm{pH}$ value of reaction solution, the reaction temperature, the initial concentration of reagents as well as the molar ratio of reagents, can control the morphology of the particles and then affect catalytic properties of the prepared samples. The samples were prepared at different reaction temperature with the initial urea and $\mathrm{FeCl}_{3} \cdot 6 \mathrm{H}_{2} \mathrm{O}$ concentration of $1.0 \mathrm{~mol} \cdot \mathrm{L}^{-1}$. Figure 9 displays the degradation efficiency of MO facilitated by the samples prepared at $70^{\circ} \mathrm{C}, 90^{\circ} \mathrm{C}$, and $110^{\circ} \mathrm{C}$. Obviously, the catalytic activity of the prepared $\beta$ - $\mathrm{FeOOH}$ for $\mathrm{MO}$ degradation is $\beta$ - $\mathrm{FeOOH}$ formed at $70^{\circ} \mathrm{C}>90^{\circ} \mathrm{C}>110^{\circ} \mathrm{C}$. Considering the particle size of the prepared $\beta$ - $\mathrm{FeOOH}$ at different temperature (see Figure 2 ), it is found that the ability of the prepared $\beta$-FeOOH in improving $\mathrm{MO}$ degradation decreases with the increase of the sample particles sizes. As mentioned earlier, adsorption of organic compounds on catalyst surface is found to play a key role in heterogeneous catalytic process. Therefore, the specific surface area of $\beta$-FeOOH is one of important factors influencing the degradation of MO by the heterogeneous Fenton reaction. Generally, the less the particles size the higher the specific surface area. The specific surface areas of samples prepared at 70, 90 and $110^{\circ} \mathrm{C}$ were determined to be 60,49 , and $31 \mathrm{~m}^{2} \cdot \mathrm{g}^{-1}$, respectively. Thus, it is clear that an increase of the specific surface area of $\beta$-FeOOH is favorable for the enhancement of the heterogeneous photocatalytic performance. This result is accordance to the conclusion drawn from the $\mathrm{Fe}_{2} \mathrm{O}_{3}$ photocatalyst [23].

Figure 10(a) shows the influence of the initial urea and $\mathrm{FeCl}_{3} \cdot 6 \mathrm{H}_{2} \mathrm{O}$ concentration on $\mathrm{MO}$ degradation efficiency facilitated by the $\beta$ - $\mathrm{FeOOH}$ prepared at $90^{\circ} \mathrm{C}$. It is noted that the synthesized $\beta$ - $\mathrm{FeOOH}$ exhibits the increase of catalytic efficiency with the decrease of the initial urea and $\mathrm{FeCl}_{3} \cdot 6 \mathrm{H}_{2} \mathrm{O}$ concentration. For example, the degradation efficiency of $\mathrm{MO}$ facilitated by the prepared $\beta$ - $\mathrm{FeOOH}$ increased from $75.50 \%$ to $88.71 \%$ when the initial concentration of urea and $\mathrm{FeCl}_{3} \cdot 6 \mathrm{H}_{2} \mathrm{O}$ decreased from 1.0 to $0.1 \mathrm{~mol} \cdot \mathrm{L}^{-1}$ at the UV irradiation time of 30 minutes. In order to investigate the effect of $\beta$-FeOOH formed at different initial molar ratios of urea to $\mathrm{Fe}^{3+}$ on the MO degradation efficiency, $\beta$ - $\mathrm{FeOOH}$ samples were prepared at $90^{\circ} \mathrm{C}$ with fixed $\mathrm{Fe}^{3+}$ concentration of 1.0 $\mathrm{mol} \cdot \mathrm{L}^{-1}$ but with different urea concentration. Figure 10(b) indicates that catalytic efficiency of the synthesized $\beta$-FeOOH increases with the decrease of the molar ratios of urea to $\mathrm{Fe}^{3+}$. For instance, the degradation efficiency of MO facilitated by the prepared $\beta$-FeOOH enhanced from $48.22 \%$ to $86.39 \%$ when the molar ratios of urea to $\mathrm{Fe}^{3+}$ decreased from 1.5 to 0.5 at the UV irradiation time of 30 minutes. Comparing the results obtained from Figures 10(a) and (b), it is found that degradation efficiency of MO facilitated by the prepared $\beta$ - $\mathrm{FeOOH}$ decreased with the increase of the urea concentration in reaction solution. Based on Equations (4) and (5), the growth rate of $\beta$ - $\mathrm{FeOOH}$ nanorods became fast with the increase of the reaction solution $\mathrm{pH}$ value. However, the $\mathrm{pH}$ value of the reaction solution increased with the in- 


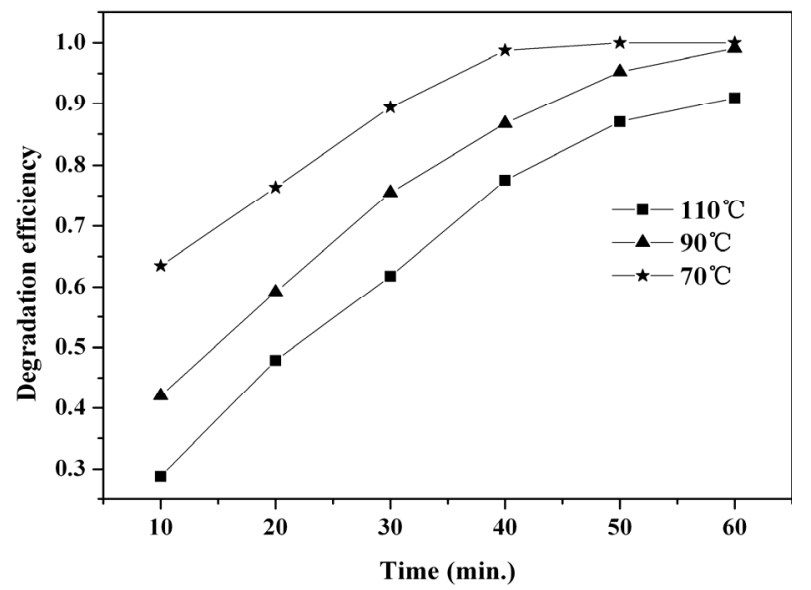

Figure 9. Effect of synthesis temperature on MO degradation efficiency.

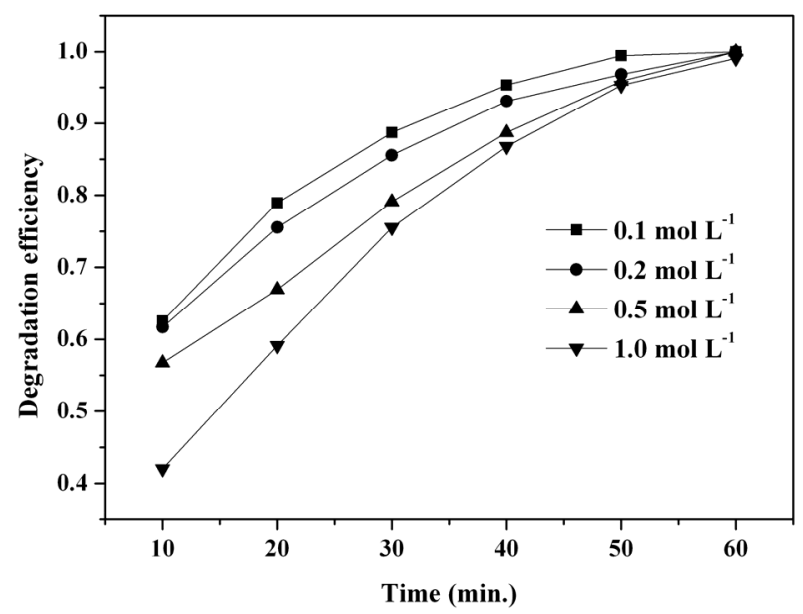

(a)

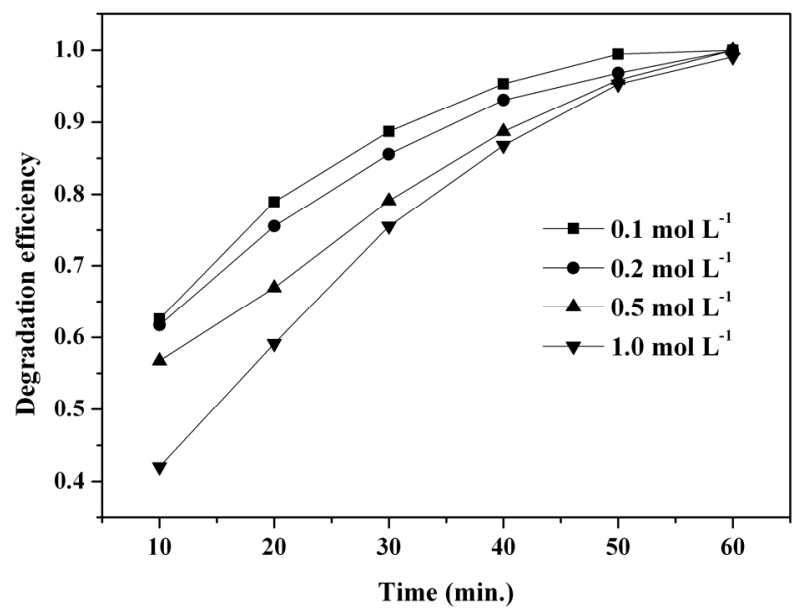

(b)

Figure 10. Effect of a urea and $\mathrm{FeCl}_{3} \cdot 6 \mathrm{H}_{2} \mathrm{O}$ concentration and $b$ different molar ratios of urea to $\mathrm{Fe}^{3+}$ on MO degradation efficiency.

crease of the urea concentration (as shown in Equations (2) and (3)). Therefore, $\beta$-FeOOH nanorods could grow faster in the reaction solution with higher urea concentration, which would lead to the rapid decrease in the specific surface area and the heterogeneous photocatalytic performance deterioration of the prepared $\beta$-FeOOH samples.

\section{Conclusion}

By using a facile and an environmental friendly hydrothermal route, akaganeite rod-shaped nanostructures were prepared successfully with the urea as homogeneous precipitant. $\beta$-FeOOH catalysts loading, $\mathrm{H}_{2} \mathrm{O}_{2}$ concentration and initial $\mathrm{pH}$ have an important effect on the degradation efficiency of MO azo dye. The catalytic activity of the synthesized $\beta$-FeOOH is also closely related to the morphology of the synthesized nanostructures that is regulated, to a great extent, by the synthesis conditions including reaction temperature, initial concentration of urea and $\mathrm{FeCl}_{3} \cdot 6 \mathrm{H}_{2} \mathrm{O}$ as well as molar ratios of urea to $\mathrm{Fe}^{3+}$. It was shown that an increase of the specific surface area of $\beta-\mathrm{FeOOH}$ is favorable for the enhancement of the heterogeneous photocatalytic performance. The prepared $\beta$-FeOOH catalyst can overcome the drawback of a narrow $\mathrm{pH}$ range of homogeneous Fenton reaction, show good photocatalytic performance for multiple uses, and offer opportunities for practical applications in heterogeneous photocatalysis process.

\section{Acknowledgements}

This study was financially supported by the National Natural Science Foundation of China (21077053, 40930 738 ), and partly by the Nanjing Agricultural University Youth Science and Technology Innovation Foundation (Y200725). The authors would like to thank Mr. Jinlong Geng and Mrs. Jing Guo for their excellent technical assistance.

\section{REFERENCES}

[1] H. Park and W. Choi, "Visible Light and Fe(III)-Mediated Degradation of Acid Orange 7 in the Absence of $\mathrm{H}_{2} \mathrm{O}_{2}$," Journal of Photochemistry and Photobiology A: Chemistry, Vol. 159, No. 3, 2003, pp. 241-247. http://dx.doi.org/10.1016/S1010-6030(03)00141-2

[2] K. Dutta, S. Mukhopadhyay, S. Bhattacharjee and B. Chaudhuri, "Chemical Oxidation of Methylene Blue Using a Fenton-Like Reaction," Journal of Hazardous Materials, Vol. 84, No. 1, 2001, pp. 57-71. http://dx.doi.org/10.1016/S0304-3894(01)00202-3

[3] S. Netpradit, P. Thiravetyan and S. Towprayoon, "Adsorption of Three azo Reactive Dyes by Metal Hydroxide Sludge: Effect of Temperature, pH, and Electrolytes," Journal of Colloid and Interface Science, Vol. 270, No. 2, 2004, pp. 255-261.

http://dx.doi.org/10.1016/j.jcis.2003.08.073

[4] F. Wu and N. S. Deng, "Photochemistry of Hydrolytic 
Iron (III) Species and Photoinduced Degradation of Organic Compounds. A Minireview," Chemosphere, Vol. 41, No. 8, 2000, pp. 1137-1147. http://dx.doi.org/10.1016/S0045-6535(00)00024-2

[5] J. He, W. H. Ma, J. J. He, J. C. Zhao and J. C. Yu, "Photooxidation of azo Dye in Aqueous Dispersions of $\mathrm{H} 2 \mathrm{O} 2 / \alpha-\mathrm{FeOOH}$," Applied Catalysis B: Environmental, Vol. 39, No. 3, 2002, pp. 211-220. http://dx.doi.org/10.1016/S0926-3373(02)00085-1

[6] J. Fan, Y. H. Guo, J. J. Wang and M. H. Fan, "Rapid Decolorization of azo Dye Methyl Orange in Aqueous Solution by Nanoscale zerovalent Iron Particles," Journal of Hazardous Materials, Vol. 166, No. 2-3, 2009, pp. 904-910. http://dx.doi.org/10.1016/j.jhazmat.2008.11.091

[7] J. Guo, Y. Y. Du, Y. Q. Lan and J. D. Mao, "Photodegradation Mechanism and Kinetics of Methyl Orange Catalyzed by $\mathrm{Fe}(\mathrm{III})$ and Citric Acid," Journal of Hazardous Materials,Vol. 186, No. 2-3, 2011, pp. 2083-2088. http://dx.doi.org/10.1016/j.jhazmat.2010.12.112

[8] D. Gumy, F.-I. Pilar, S. Malato, C. Pulgarin, O. Enea and J. Kiwi, "Supported $\mathrm{Fe} / \mathrm{C}$ and $\mathrm{Fe} / \mathrm{Nafion} / \mathrm{C}$ Catalysts for the Photo-Fenton Degradation of Orange II under Solar Irradiation," Catalysis Today, Vol. 101, No. 3-4, 2005, pp. 375-382. http://dx.doi.org/10.1016/j.cattod.2005.03.036

[9] C.-P. Huang and Y.-H. Huang, "Comparison of Catalytic Decomposition of Hydrogen Peroxide and Catalytic Degradation of Phenol by Immobilized Iron Oxides," Applied Catalysis A: General, Vol. 346, No., 2008, pp. 140. http://dx.doi.org/10.1016/j.apcata.2008.05.017

[10] Z.-Y. Yuan, T.-Z. Ren and B.-L. Su, "Surfactant Mediated Nanoparticle Assembly of Catalytic Mesoporous Crystalline Iron Oxide Materials," Catalysis Today, Vol. 93-95, 2004, pp. 743-750.

http://dx.doi.org/10.1016/j.cattod.2004.06.092

[11] M. Benz, A. M. van der Kraan and R. Prins, "Reduction of Aromatic Nitrocompounds with Hydrazine Hydrate in the Presence of an Iron Oxide Hydroxide Catalyst: II. Activity, X-Ray Diffraction and Mössbauer Study of the Iron Oxide Hydroxide Catalyst," Applied Catalysis A: General, Vol. 172, No. 1, 1998, pp. 149-157. http://dx.doi.org/10.1016/S0926-860X(98)00111-2

[12] Z. Yaping, H. Jiangyong and C. Hongbin, "Elimination of Estrogen and Its Estrogenicity by Heterogeneous PhotoFenton Catalyst $\beta$-FeOOH/Resin," Journal of Photochemistry and Photobiology A: Chemistry, Vol. 212, No. 2-3, 2010, pp. 94-100. http://dx.doi.org/10.1016/j.jphotochem.2010.04.001

[13] J. Krýsa, J. Jirkovský, O. Bajt and G. Maihot, "Competitive Adsorption and Photodegradation of Salicylate and Oxalate on Goethite," Catalysis Today, Vol. 161, No. 1, 2011, pp. 221-227. http://dx.doi.org/10.1016/j.cattod.2010.11.083

[14] J. G. Parsons, C. Luna, C. E. Botez, J. Elizalde and J. L. Gardea-Torresdey, "Microwave-Assisted Synthesis of
iron(III) Oxyhydroxides/Oxides Characterized Using Transmission Electron Microscopy, X-Ray Diffraction, and X-Ray Absorption Spectroscopy," Journal of Physics and Chemistry of Solids, Vol. 70, No. 3-4, 2009, pp. 555-560. http://dx.doi.org/10.1016/j.jpcs.2008.12.017

[15] C. Wei and Z. Nan, "Effects of Experimental Conditions on One-Dimensional Single-Crystal Nanostructure of $\beta$ FeOOH," Materials Chemistry and Physics, Vol. 127, No. 1-2, 2011, pp. 220-226. http://dx.doi.org/10.1016/j.matchemphys.2011.01.062

[16] Y. P. Zhao and J. Y. Hu, "Photo-Fenton Degradation of $17 \beta$-Estradiol in Presence of $\alpha$-FeOOHR and H2O2," Applied Catalysis B: Environmental, Vol. 78, No. 3-4, 2008, pp. 250-258. http://dx.doi.org/10.1016/j.apcatb.2007.09.026

[17] G. Tong, J. Guan and Q. Zhang, "Goethite Hierarchical Nanostructures: Glucose-Assisted Synthesis, Chemical Conversion into Hematite with Excellent Photocatalytic Properties," Materials Chemistry and Physics, Vol. 127, No. 1-2, 2011, pp. 371-378.

http://dx.doi.org/10.1016/j.matchemphys.2011.02.021

[18] J. C. Villalba, V. R. L. Constantino and F. J. Anaissi, "Iron Oxyhydroxide Nanostructured in Montmorillonite clays: Preparation and Characterization," Journal of Colloid and Interface Science, Vol. 349, No. 1, 2010, pp. 4955. http://dx.doi.org/10.1016/j.jcis.20s10.04.057

[19] A. Millan, A. Urtizberea, E. Natividad, F. Luis, N. J. O. Silva, F. Palacio, I. Mayoral, M. L. Ruiz-Gonzalez, J. M. Gonzalez-Calbet, P. Lecante and V. Serin, "Akaganeite Polymer Nanocomposites," Polymer, Vol. 50, No. 5, 2009, pp. 1088-1094. http://dx.doi.org/10.1016/j.polymer.2009.01.034

[20] M. Muruganandham, J.-S. Yang and J. J. Wu, "Effect of Ultrasonic Irradiation on the Catalytic Activity and Stability of Goethite Catalyst in the Presence of $\mathrm{H}_{2} \mathrm{O}_{2}$ at Acidic Medium," Industrial \& Engineering Chemistry Research, Vol. 46, No. 3, 2007, pp. 691-698. http://dx.doi.org/10.1021/ie060752n

[21] M. Sui, L. Sheng, K. Lu and F. Tian, "FeOOH Catalytic Ozonation of Oxalic Acid and the Effect of Phosphate Binding on Its Catalytic Activity," Applied Catalysis B: Environmental, Vol. 96, No., 2010, pp. 94. http://dx.doi.org/10.1016/j.apcatb.2010.02.005

[22] J.-Q. Chen, D. Wang, M.-X. Zhu and C.-J. Gao, "Study on Degradation of Methyl Orange Using Pelagite as Photocatalyst," Journal of Hazardous Materials, Vol. 138, No. 1, 2006, pp. 182-186. http://dx.doi.org/10.1016/j.jhazmat.2006.05.049

[23] L. Song and S. Zhang, "Formation of $\alpha-\mathrm{Fe} 2 \mathrm{O} 3 / \mathrm{FeOOH}$ Nanostructures with Various Morphologies by a Hydrothermal Route and Their Photocatalytic Properties," Colloids and Surfaces A: Physicochemical and Engineering Aspects, Vol. 348, No. 1-3, 2009, pp. 217-220. http://dx.doi.org/10.1016/j.colsurfa.2009.07.022 